\title{
EVALUASI KINERJA SISTEM PENDINGIN SEKUNDER RSG GAS BERDASARKAN LAPORAN OPERASI REAKTOR
}

\author{
R.Kusumastuti ${ }^{1}$, Setyo Budi Utomo ${ }^{2}$, Sofia Loren Butar-butar ${ }^{3}$ \\ ${ }^{1,3}$ Pusat Teknologi dan Keselamatan Reaktor Nuklir, Gd.80. Kawasan Puspiptek, Setu, \\ Tangerang Selatan, 15310 \\ ${ }^{2}$ Pusat Reaktor Serba Guna, Gd. Kawasan Puspiptek, Setu, Tangerang Selatan, 15310 \\ Email: rahayu@batan.go.id
}

\begin{abstract}
ABSTRAK
EVALUASI KINERJA SISTEM PENDINGIN SEKUNDER RSG GAS BERDASARKAN LAPORAN OPERASI REAKTOR. Reaktor Serba Guna Siwabessy (RSG GAS) adalah reaktor serbaguna yang dibangun sejak Tahun 1983. RSG GAS berdaya $30 \mathrm{MW}$ th, dengan fluks neutron rata-rata $10^{14} \mathrm{n} / \mathrm{cm}^{2}$.detik yang berasal dari reaksi fisi. Reaktor ini dibangun untuk berbagai eksperimen dan juga mendukung sediaan produksi radiofarmaka di Indonesia. Pada saat ini RSG GAS telah berumur lebih dari 30 tahun dan telah mendapatkan izin operasi dari Bapeten. RSG GAS mempunyai dua sistem pendingin yaitu sistem pendingin primer dan sekunder. Kedua sistem pendingin menggunakan air sebagai fluidanya. Kualitas air pendingin sekunder sesuai yang dipersyaratkan juga harus dipenuhi untuk menekan terjadinya korosi, kerak dan lumut/mikroorganisme. Dengan penanganan sistem pendingin yang baik diharapkan keandalan operasi RSG GAS dapat terjaga. Penilaian Keselamatan Berkala (PKB) dilakukan reaktor GA.Siwabessy dalam setiap 10 tahun sekali. PKB periode 2005 - 2015 telah di laporkan. Penelitian ini dilakukan untuk mengevaluasi kinerja sistem pendingin sekunder reaktor G.A Siwabessy dari Tahun 2016 - 2018. Tujuan evaluasi adalah untuk mengetahui kinerja sistem pendingin sekunder dalam rangka mendukung dokumen PKB pada periode 10 tahun berikutnya. Metodologi yang dilakukan adalah dengan cara evaluasi data Laporan Operasi Reaktor (LOR) RSG GAS dari Tahun 2016 -2018. Hasil evaluasi LOR dari siklus operasi teras 89-95 menunjukkan tidak ada anomali data hasil operasi reaktor terkait kinerja sistem pendingin sekunder. Berdasarkan hasil evaluasi dapat disimpulkan bahwa pengoperasian RSG GAS masih berada pada batas operasi yang normal.
\end{abstract}

Kata kunci : evaluasi, kinerja, pendingin sekunder, RSG GAS, laporan operasi

\begin{abstract}
Performance Evaluation of The Secondary Cooling System RSG GAS Reactor Research Based On Reactors Operations Report. The Siwabessy Multipurpose Reactor (RSG GAS) is a multipurpose reactor that was built since 1983. RSG GAS has power of $30 \mathrm{MWth}$, with an average neutron flux fission of $10^{14} \mathrm{n} / \mathrm{cm} 2$.dec. This reactor was built for various experiments, especially for the production of radiopharmaceuticals. Currently, RSG GAS is more than 30 years old, the operating permit has been issued from Bapeten.The reactor has two cooling systems, namely primary and secondary cooling systems that use the water as their fluid. The quality of secondary cooling water as required must also be met to suppress corrosion, scale and microorganisms. The reliability of RSG GAS operation can be maintained by an optimum handling. Periodic Safety Assessment (PKB) reactor is carried out every 10 years.PKB for the period 2005 - 2015 has been reported. This research was conducted to evaluate the performance of the RSG GAS secondary cooling system from 2016 to 2018. The purpose of the evaluation is to determine the performance of the secondary cooling system in order to support the PKB document in the next 10 years period.The methodology used is to evaluate the RSG GAS Reactor Operation Report data from 2016 - 2018.The evaluation results from the 89-95
\end{abstract}


core operating cycle show that there are no data anomalies on the results of reactor operation related to the performance of the secondary cooling system.Based on the results of the evaluation, it can be concluded that the reactor operation is on normal operating limits.

Keywords: evaluation, performance, secondary coolant, RSG GAS, operation report 


\section{PENDAHULUAN}

Reaktor Serba Guna Siwabessy dibangun sejak Tahun 1983. Pencapaian kritis pertama dicapai pada Bulan Juli 1987 dan kemudian diresmikan oleh Presiden RI pada tanggal 20 Agustus 1987. RSG-GAS mempunyai daya termal maksimum $30 \mathrm{MW}$ dan mempunyai fluks neutron rata-rata 1014 $\mathrm{n} / \mathrm{cm} 2$.detik yang berasal dari reaksi fisi. RSG-GAS merupakan reaktor riset dengan jenis kolam berbahan bakar U3Si2Al dengan pengayaan 235U sebesar 19,75\% [1].

Reaktor ini mempunyai dua sistem pendingin yaitu sistem pendingin primer dan sekuder. Kedua pendingin menggunakan air sebagai fluida pendinginnya. Air demineralisasi pada sistem pendingin primer berfungsi sebagai pendingin reaktor, moderator neutron serta perisai neutron termal. Sebagai pendingin, air demineralisasi ini berfungsi memindahkan panas yang timbul sebagai akibat reaksi fisi di teras reaktor [2]. Radiasi neutron pada teras reaktor akan mendegradasi air menjadi spesi aktif. Salah satu bentuk degradasi yaitu terbentuknya senyawa oksidator seperti $\mathrm{O}_{2}$ dan $\mathrm{H}_{2} \mathrm{O}_{2}$ yang memicu terjadinya reaksi oksidasi, reaksi korosi. Reaksi korosi akan membentuk oksida logam dan dapat mengendap di tempat yang tidak diinginkan, seperti di alat penukar panas (heat exchanger) yang dapat menurunkan efisiensi daya tukar panas sehingga akan memperpendek usia pengoperasian.
Sistem pendingin RSG-GAS terdiri dari sistem pendingin primer dan sistem pendingin sekunder ditunjukkan pada Gambar 1 [1]. Fungsi sistem pendingin primer dan sekunder adalah untuk menjamin suhu yang aman di dalam teras dan reflektor selama reaktor beroperasi normal sampai daya termal desain [3] Selama reaktor beroperasi pada daya tinggi, panas yang dibebaskan di dalam teras dan sekitar reflektor diambil oleh air sistem pendingin primer dengan cara mengalirkan air pendingin lewat celah bahan bakar, panas dipindahkan ke sistem pendingin sekunder melalui sistem penukar panas kemudian panas tersebut dibuang ke atmosfir melalui menara pendingin beraliran udara paksa [4]

Sistem pendingin sekunder menggunakan air yang berasal dari PAM PUSPIPTEK tanpa pengolahan lebih lanjut. Diagram alir pengelolaan air pada reaktor RSG-GAS ditunjukkan pada Gambar 2 [5]. Kualitas air pendingin sekunder juga dipersyaratkan dan membutuhkan penanganan untuk menekan terjadinya korosi, kerak dan lumut/mikroorganisme [6], [7]. 


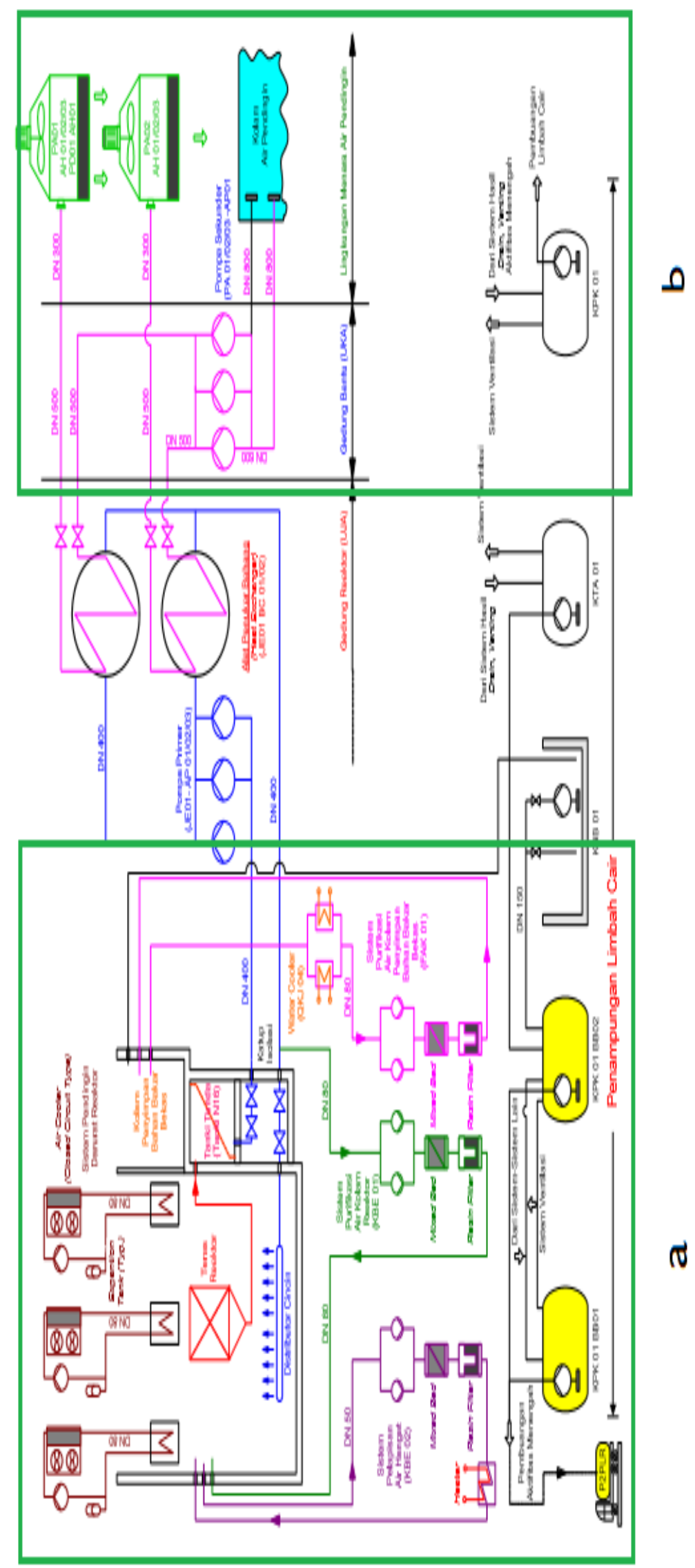

Gambar 1. a. Sistem pendingin primer dan b. Sistem pendingin sekunder RSG-GA Siwabessy [1][11] 


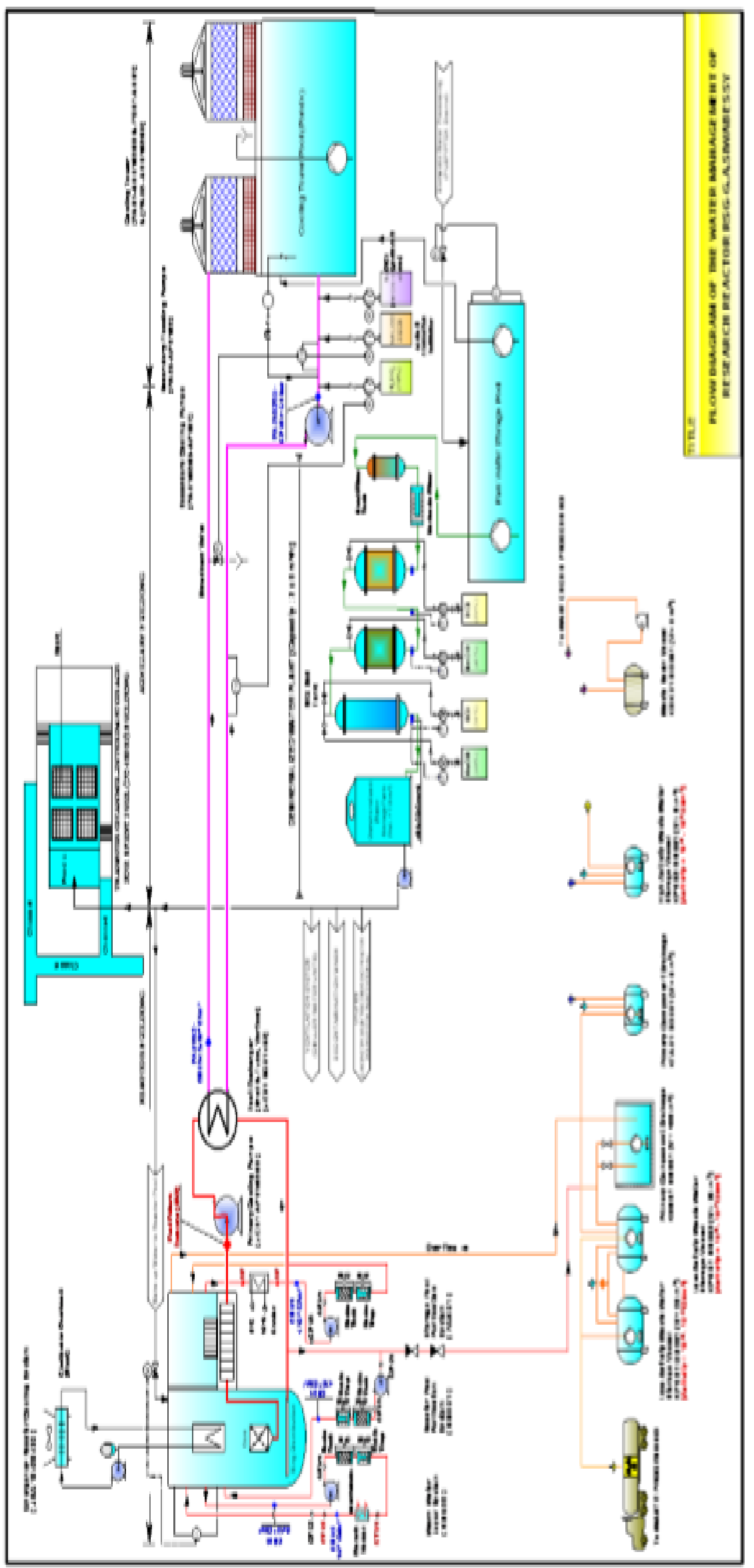

Gambar 2. Diagram alir pengelolaan air RSG GAS [12] 
Sistem pendingin sekunder merupakan tempat untuk pembuangan panas yang terakhir dari reaktor. Panas yang terbentuk pada sistem primer dipindahkan ke sistem sekunder melalui alat penukar panas dan akhirnya dibuang ke atmosfer melalui menara pendingin. Sistem ini mampu membuang panas total $33000 \mathrm{~kW}$ [13]. Tiap bagian pemipaan sistem pendingin sekunder terdiri dari pompa, alat penahan panas, pipa dan menara pendingin [8]-[10]. Sistem pendingin sekunder didisain mampu mendinginkan air primer, sehingga suhu aliran inlet ke kolam reaktor tidak melebihi $400^{\circ} \mathrm{C}$ [14]. Spesifikasi air pendingin sekunder ditunjukkan pada Tabel 1. Komponen sistem pendingin sekunder terdiri dari: tiga (3) buah pompa yang terbuat dari besi karbon tuang berbentuk keong yang dilengkapi dengan sambungan untuk venting dan drainase.

Tabel 1. Spesifikasi kualitas air pendingin sekunder [15]

\begin{tabular}{ll}
\hline \multicolumn{1}{c}{ Parameter } & \multicolumn{1}{c}{ Nilai } \\
\hline $\mathrm{pH}$ & $6,5-8$ \\
Konduktivitas Normal & $850-950$ mikro S/cm \\
Konduktivitas Maks & $1500 \mathrm{mikro} \mathrm{S/cm}$ \\
$\mathrm{Kalsium}^{2}$ sebagai $\mathrm{CaCO}_{3}$ maks & $280 \mathrm{ppm}$ \\
$\mathrm{SO}_{4}{ }^{2-}$ & $320 \mathrm{ppm}$ \\
$\mathrm{Hardness}$ total maks & $480 \mathrm{ppm}$ \\
$\mathrm{Fe}$ total maks & $1 \mathrm{ppm}$ \\
$\mathrm{Cl}^{-}$maks & $155,5 \mathrm{ppm}$ \\
Laju korosi & $3 \mathrm{mpy}$ \\
Total bakteri & $10^{6} \mathrm{bakteri} / \mathrm{ml}$ \\
\hline
\end{tabular}

penukar panas, sistem make up water. Komponen tersebut harus berfungsi dengan baik agar operasi reaktor berjalan lancar. Perawatan sistem reaktor haruslah dilakukan sesuai dengan jadwal yang telah dilakukan. Oleh karena itu perlu dilakukan evaluasi komponen reaktor secara berkala untuk memastikan sistem masih beroperasi dengan baik. Penelitian ini dilakukan dengan cara melakukan evaluasi kinerja sistem pendingin sekunder reaktor GA.Siwabessy untuk periode siklus operasi teras 89-95. Hasil evaluasi ini akan menjadi penilaian terhadap kinerja komponen reaktor.

\section{METODOLOGI}

Metodologi dilakukan dengan evaluasi data laporan operasi reaktor RSG GAS tahun 2016 - 2018 (siklus operasi 89 sampai dengan 95), terkait parameter operasi sistem pendingin sekunder. Evaluasi meliputi pengamatan, pengumpulan dan analisis data dari lembaran data operasi teras reaktor 89 s/d 95. Dari proses evaluasi ini, diharapkan bisa dijadikan patokan dalam menjaga kualitas air pendingin sekunder RSG GAS yang harus sesuai standar. Penanganan yang benar dan optimal, diharapkan keandalan operasi RSG GAS dapat terjaga.

Komponen sistem pendingin sekunder reaktor GA Siwabessy antara lain berupa pompa, katup, sistem pembersih pipa 


\section{HASIL DAN PEMBAHASAN}

Pengoperasian reaktor pada daya 15 MW dengan energi yang dibangkitkan sebesar 640,5971 MWD menggunakan sebanyak 40 elemen bakar standar jenis $\mathrm{U}_{3} \mathrm{Si}_{2}$-Al ditambah 8 elemen bakar kendali jenis $\mathrm{U}_{3} \mathrm{Si}_{2}-\mathrm{Al}$ dengan berat total U-235 pada awal siklus sebesar 8642,46 gram. Berat total U-235 akhir siklus 7893,20 gram. Fraksi bakar rerata pada awal siklus sebesar 24,24 $\%$ dan fraksi bakar rerata akhir siklus sebesar $30,84 \%$. Fraksi bakar tertinggi di teras 89 ini sebesar 53,15 \% untuk Elemen Bakar Kendali dan 56,82 \% untuk Elemen Bakar Standar. Nilai tersebut masih dibawah fraksi bakar maksimum yang diijinkan yaitu sebesar 59,59\%[16]. Pengoperasian reaktor berlangsung selama 43,45 hari artinya sepadan dengan $36,51 \%$ waktu yang tersedia dan 63,49\% waktunya digunakan untuk perawatan, perbaikan sistem, struktur dan komponen reaktor, pembongkaran dan pembentukan teras serta persiapan sarana operasi. Dari seluruh waktu operasi reaktor 98,76 \% digunakan untuk operasi daya tinggi, kalibrasi daya, iradiasi target produksi radioisotop dan eksperimen, sedangkan 1,24 $\%$ waktu yang tersisa digunakan untuk operasi daya rendah untuk kalibrasi batang kendali pada awal siklus. Evaluasi sistem pendingin sekunder RSG GAS dilakukan berdasar pada Laporan Operasi RSG (LOR) pada siklus operasi 89 sampai dengan 95, dengan melakukan kajian data pengukuran pada sistem pendingin sekunder saat dilakukan operasi teras reaktor.

\section{Evaluasi Sistem pendingin sekunder RSG GAS}

Pada evaluasi sistem pendingin sekunder ini, dilakukan evaluasi terhadap beberapa item, diantaranya adalah: suhu masuk dan keluar BC01, suhu masuk dan keluar BC02, laju aliran masuk dan keluar pompa 1, laju aliran masuk dan keluar pompa 2, level kolam menara pendingin, level kolam penyimpanan air, tekanan isap pompa 1 dan 2 serta $\mathrm{pH}$ dan konduktivitas air kolam pendingin sekunder RSG. Kondisi Pompa 1 meliputi: temperatur masuk dan keluar, laju alir masuk dan keluar pompa, serta tekanan isap pompa 1 adalah sebagai berikut:

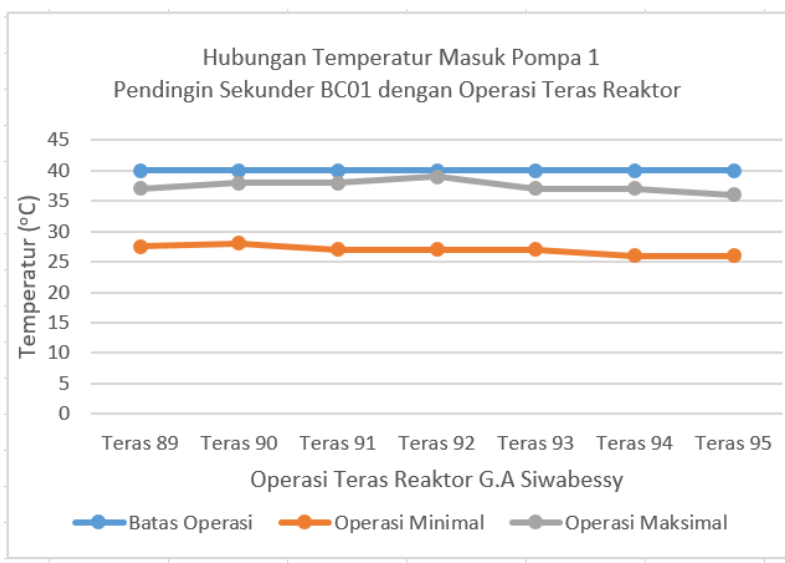

Gambar 3. Hubungan temperatur air masuk pompa 1 dengan operasi teras reaktor RSG GAS 


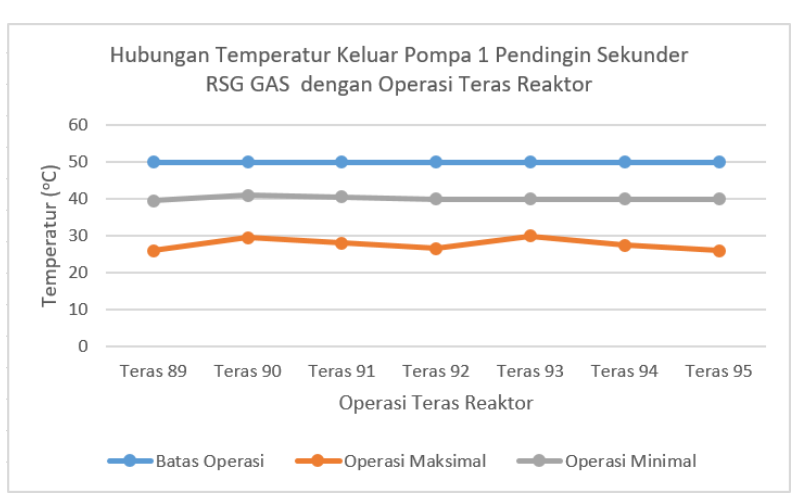

Gambar 4. Hubungan temperatur air keluar pompa 1 dengan operasi teras reaktor RSG GAS

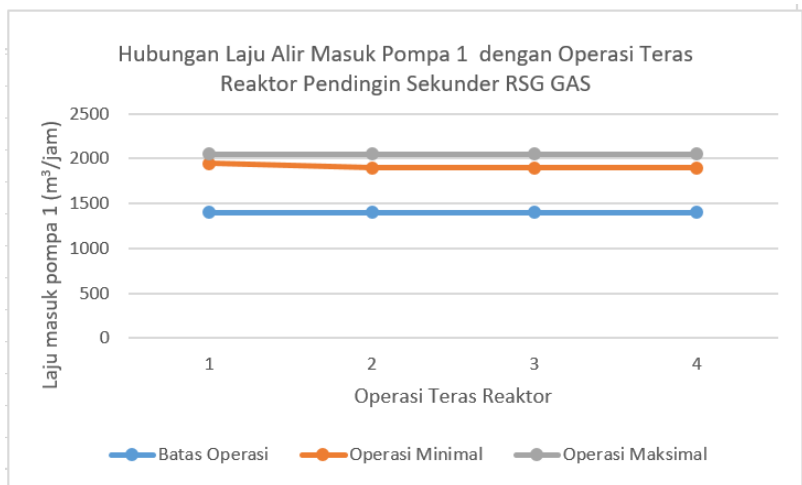

Gambar 5. Hubungan laju aliran masuk pompa 1 pendingin sekunder dengan operasi teras reaktor RSG GAS

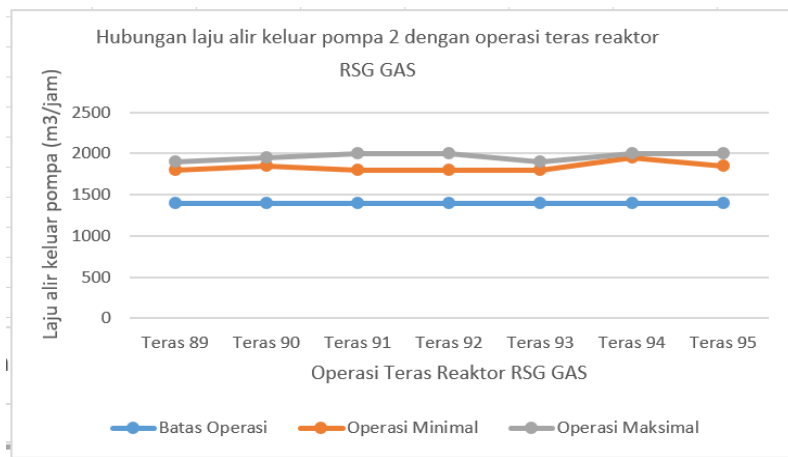

Gambar 6. Hubungan laju alir keluar pompa 1 pendingin sekunder dengan operasi teras reaktor RSG

GAS

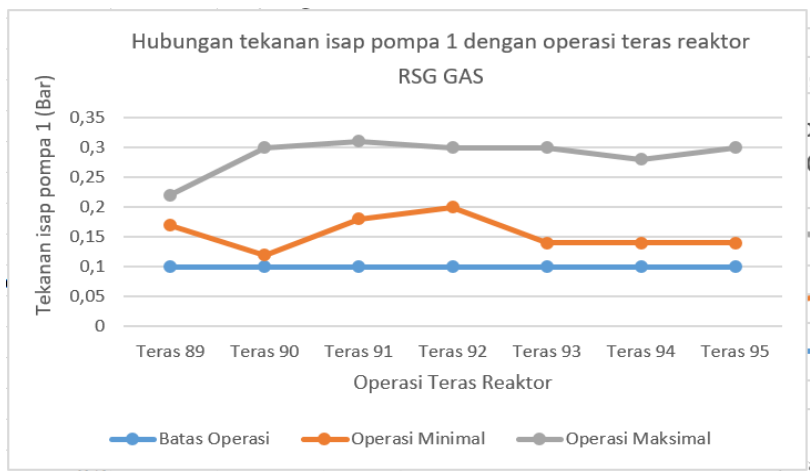

Gambar 7. Hubungan tekanan isap pompa 1 pendingin sekunder dengan operasi teras reaktor RSG

GAS
Hubungan temperatur keluar pompa 2 dengan operasi teras reaktor RSG GAS

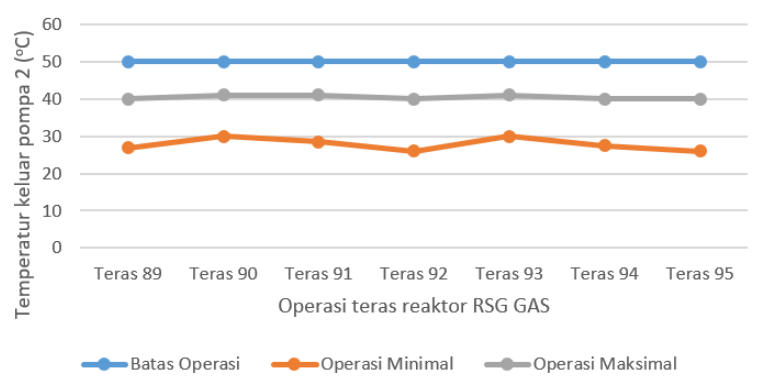

Gambar 8. Hubungan temperatur masuk pompa 2 pendingin sekunder dengan operasi teras reaktor RSG

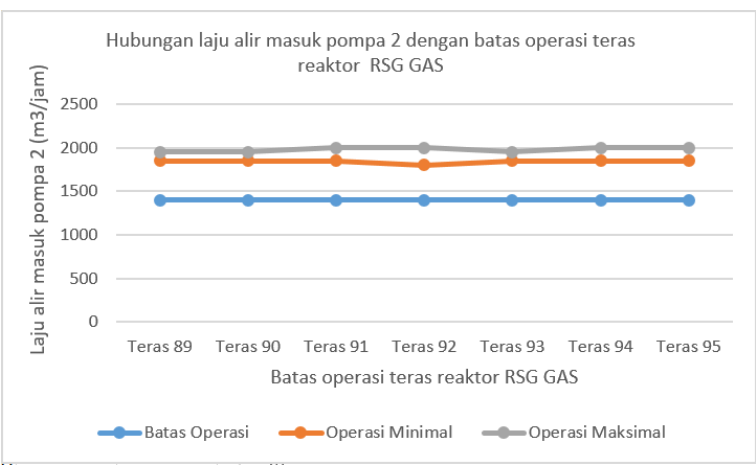

Gambar 9. Hubungan laju aliran air masuk pompa 2 dengan operasi teras reaktor RSG

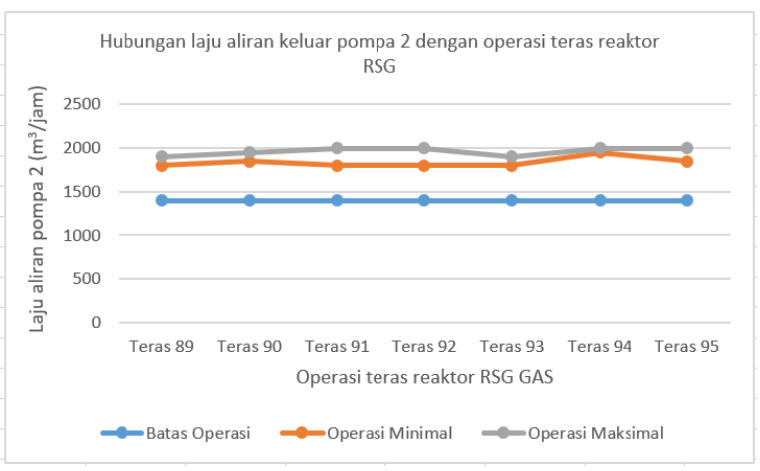

Gambar 10. Hubungan laju aliran air keluar pompa 2 dengan operasi teras reaktor RSG GAS 


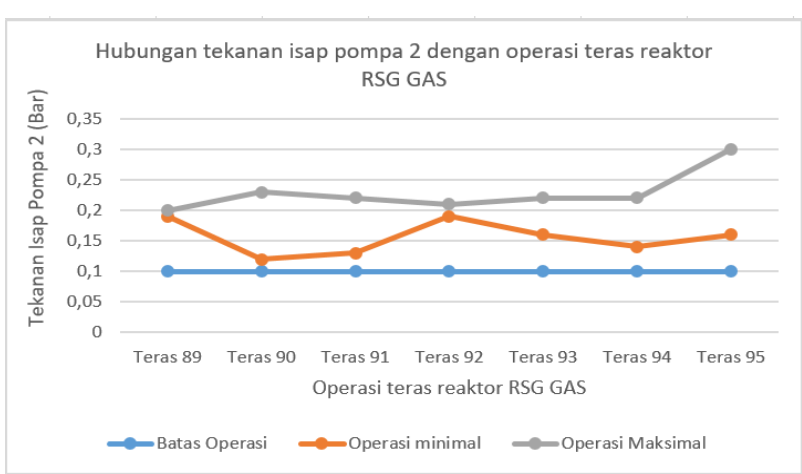

Gambar 11. Hubungan tekanan isap pompa 2 pendingin sekunder dengan operasi teras reaktor RSG GAS

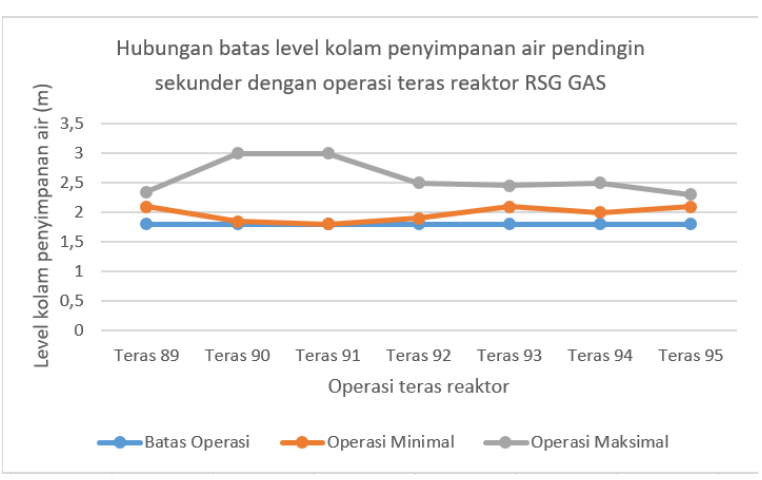

Gambar 12. Hubungan level kolam penyimpanan air pendingin sekunder dengan operasi teras reaktor RSG GAS

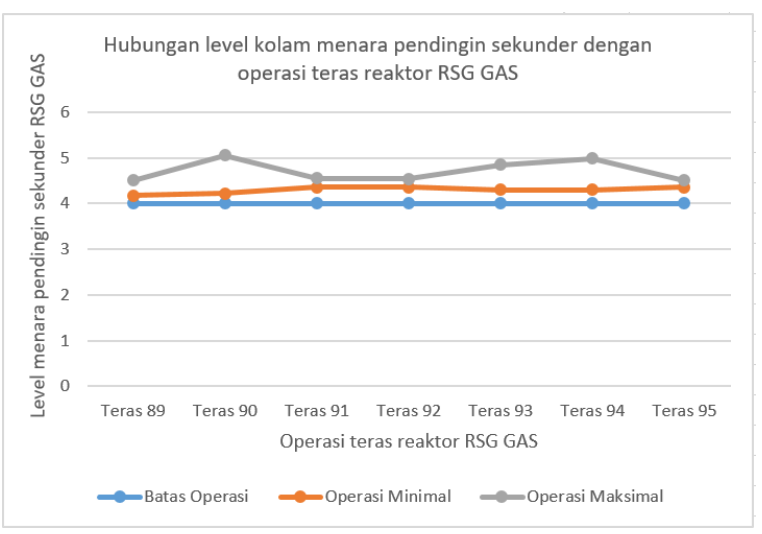

Gambar 13. Hubungan level kolam menara pendingin sekunder dengan operasi teras reaktor RSG GAS

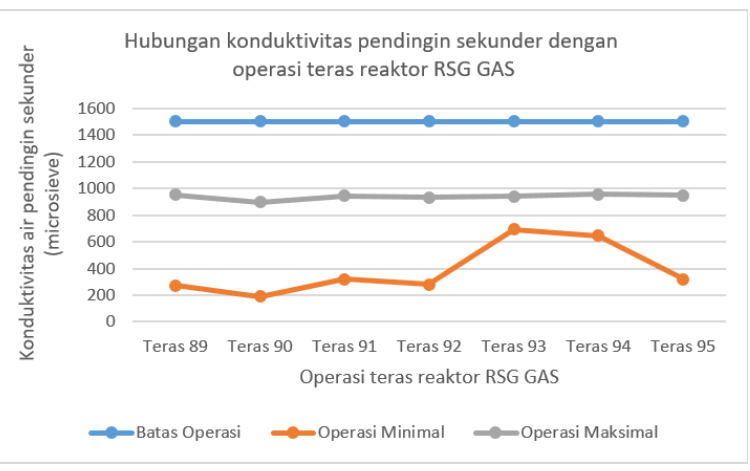

Gambar 14. Hubungan konduktivitas pendingin sekunder dengan operasi teras reaktor RSG GAS

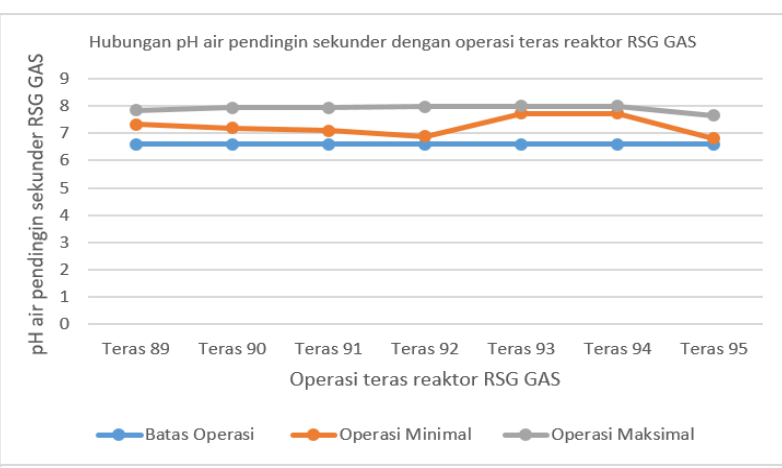

Gambar 15. Hubungan $\mathrm{pH}$ air pendingin sekunder dengan operasi teras reaktor RSG GAS 
Dari laporan operasi teras reaktor periode 89 sampai dengan 95, terlihat bahwa nilai temperatur masih di bawah batas operasi yang di persyaratkan. Pada operasi teras ke 92, batas operasi maksimal hampir mendekati batas operasi yang di persyaratkan. Tetapi masih dalam tahap yang ditoleransikan. Sehingga dapat disimpulkan bahwa pengoperasian yang wajar, tidak melebihi yang dipersyaratkan.

Gambar 4 dan 5 merupakan grafik yang menunjukkan hubungan temperatur masuk dan keluar pompa 1 dengan operasi teras reaktor RSG, terlihat bahwa pengoperasian pompa 1 masih di bawah batas operasi yang ditentukan, dalam artian pengoperasian masih dalam tahap temperatur yang di izinkan, temperatur $40^{\circ} \mathrm{C}$.

Gambar 5 dan 6 adalah grafik yang menunjukkan hubungan laju aliran masuk dan keluar pompa 1 dengan operasi teras reaktor, hal ini menunjukkan bahwa laju alir air yang masuk dan keluar pompa 1 melebihi batas minimal yang dipersyaratkan > 1400 m3/jam [17]. Hal ini menandakan aliran berjalan normal, tidak ada hambatan dalam aliran air.

Gambar 7 menunjukkan hubungan antara tekanan isap pompa dan operasi teras reaktor, hal ini memperlihatkan bahwa pompa bekerja dengan baik, pompa bekerja dengan tekanan lebih dari 0,1 bar. Pengoperasian teras reaktor dilakukan dengan mengambil nilai batas minimal dan maksimal dalam pengoperasian. Dari gambar 7 terlihat bahwa grafik operasi batas minimal dan maksimal tidaklah linier, hal ini disebabkan karena faktor mekanik yang terjadi pada pompa. Faktor vibrasi dan kesejajaran poros pompa sangat pengaruh pada pembacaan tekanan isap pompa. anomali vibrasi/gertaran disebabkan karena unbalance atau terjadinya pergeseran titik pusat massa dari titik pusat putar sehingga akan menimbulkan getaran yang tinggi. selain itu mechanical looseness mungkin bisa terjadi pada pompa isap, dimana kerenggangan baut, bantalan atau keretakan pada pondasi pompa. hal ini akan mempengaruhi terhadap daya tekanan isap pompa.

Gambar 8 menunjukkan hubungan antara temperatur masuk dan keluar pompa 2 dengan operasi teras teraktor, hal ini memperlihatkan bahwa pompa dioperasikan dengan normal, tidak melebihi batas yang dipersyaratkan. hal ini ditunjukkan dengan temperatur pengoperasian pompa tidak lebih dari $40{ }^{\circ} \mathrm{C}$.

Gambar 9 dan 10 menunjukkan hubungan laju alir masuk dan keluar pompa 2 dengan operasi teras reaktor RSG GAS, ternyata aliran air berjalan dengan tidak ada hambatan. hal ini di buktikan dengan laju aliran yang melebihi batas minimal yang di persyaratkan, yaitu $1500 \mathrm{~m}^{3} / \mathrm{jam}$.

Gambar 11 menggambarkan tekanan isap pompa 2 pendingin sekunder RSG, 
memperlihatkan bahwa grafik operasi daya isap pompa berada di atas batas operasi, hal ini menunjukan bahwa pompa mampu bekerja dengan tekanan optimal.

Gambar 12 menunjukkan hubungan level kolam penyimpanan air pendingin sekunder RSG dan operasi teras reaktor, dapat di lihat bahwa pengisian air kolam telah melebihi batas yang di persyaratkan artinya kolam pendingin sekunder telah terisi air pendingin yang cukup/normal.

Gambar 13 menunjukkan hubungan antara level kolam menara pendingin dengan operasi teras reaktor, hal ini menunjukkan bahwa level air kolam masih terisi air dengan level melebihi yang dipersyaratkan minimal.

Gambar 14 menggambarkan hubungan antara konduktivitas sistem pendingin sekunder dengan operasi teras reaktor, hal ini memperlihatkan bahwa konduktivitas dalam air tersebut tidak melebihi batas yang di persyaratkan, $<1500$ microsieve.

Gambar 15 menunjukkan hubungan antara $\mathrm{pH}$ pada air pendingin sekunder dengan operasi teras reaktor RSG GAS, hal ini dapat dilihat bahwa $\mathrm{pH}$ dalam sistem pendingin sekunder telah sesuai dengan standar yang di persyaratkan, yaitu antara 6,5 dan 8. Hal ini normal, karena $\mathrm{pH}$ dalam air pendingin sekunder tersebut memang dijaga sedemikian hingga mempunyai $\mathrm{pH}$ seperti tersebut, dengan penambahan zat kimia di dalam nya, seperti zat pembunuh microorganisme, pemberantas lumut dan penghilang kerak serta asam sulfat sebagai penyeimbang $\mathrm{pH}$.

\section{KESIMPULAN}

Berdasarkan hasil evaluasi Laporan Operasi RSG GAS untuk siklus teras 89 s/d 95 dapat disimpulkan bahwa tidak ada anomali atau penyimpangan data operasi reaktor, sehingga dapat dikatakan bahwa operasi RSG berjalan normal, dan masih berada dalam batas yang dipersyaratkan.

\section{UCAPAN TERIMAKASIH}

Penulis mengucapkan terimakasih kepada kepada Pusat PTKRN yang telah memberikan kesempatan untuk melakukan penelitian di PRSG.

\section{DAFTAR PUSTAKA}

[1] R. KUSUMASTUTI, SUMARYO, SRIYONO, 'Effect of Dukem Inhibitor on Aisi 1010 in The Secondary Cooling System of RSG GAS', J. Tek. Reaktor. Nukl., vol. 20, no. 2, 2018.

[2] I.KUNTORO, SRIYONO, M. SUBEKTI , G.R. SUNARYO, A. ROKHIM, TAXWIM, J. SUKMANA., 'Overview of the Application of the Specific Safety Requirements to BATAN Research Reactors', IOP Conf. Series: Journal of Physics: Conf. Series 1, vol. 1198, pp. 1-7, 2018.

[3] E. RATNAWATI, D. T. JATMIKO, M.G. PERMADI., Studi Pengotor Pada Pendingin Primer Reaktor RSG GAS Setelah 30 Tahun Beroperasi, J. Ganendra,Vol 21, No.1, 2018.

[4] D.E. LESTARI, S.B UTOMO, SUHARTONO.,Keandalan Sistem 
Pemurnian Terhadap Kualitas Air Pendingin Primer RSG GAS, Prosiding Seminar Keselamatan Nuklir 2 - 3, 2006,ISSN: 1412-3258.

[5] DJARUDDIN HASIBUAN, Y. B. MARSAHALA,P.H.SETIAWAN.,Pe nentuan Degradasi Kemampuan Sistem Pemipaan Pendingin Sekunder RSG GAS, J. Perangkat Nuklir, Vol 05, No.01, 2011.

[6] EDWIN RIZKI SAFITRA, D.E.LESTARI., Studi Sistem Injeksi Inhibitor Korosi Terhadap Kandungan Ortophosphat dan Seng Sebagai Parameter pengendali Korosi Pada Sistem Pendingin Sekunder RSG GAS, Journal of Science and Applicative Technology, vol. 1, pp. 102-105, 2017.

[7] D. M. BASTIDAS, M.CRIADO, S.FAJARDO, A.LA IGLESIA AND J.M. BASTIDAS., Corrosion Inhibition Mechanism of Phosphates for Early-age Rinforced Mortar in the Presence of Chlorides, Elsevier:J.Cement and Concrete Composites, vol. 61, pp. 1-6, 2015

[8] I. KARLIANA, Identifikasi Microba Dalam Air Pendingin Sekunder RSG GAS, Sigma Epsilon, no. 1410, pp. 265-270.

[9] G.R.SUNARYO., Pengendalian Proses Korosi Pada Sistem Pendingin Sekunder RSG GAS $30 \mathrm{MW}$, Prosiding Seminar Nasional ke-19 Teknologi dan Keselamatan PLTN Serta Fasilitas Nuklir, 2013

[10] S. B. UTOMO, D.E.LESTARI., Pertumbuhan Mikroorganisme Pada Air Pendingin Sekunder RSG-GAS, Seminar Nasional IV SDM Teknologi Nuklir, 2008.

[11] G.R.SUNARYO, 'Surveillance Management For Secondary Water Cooling Quality of RSG GAS', Jurnal Sains dan Teknologi Nuklir Indonesia Indonesian Journal of Nuclear Science and Technology, vol. 18, 2017.

[12] SRIYONO, R.KUSUMASTUTI, S.L.BUTAR-BUTAR, A.HAFID, G.R.SUNARYO, D.E.LESTARI.,The
Debris Particles Analysis of RSG GAS Coolant to Anticipate Sediment Induced Corrosion, Jurnal Pengembangan Energi Nuklir, vol. 18, no. 1, pp. 11-21, 2016.

[13] B.MURJATI, ROYADI, AMRIL., Analisis Penurunan Beda Tekanan Di Pompa Pendingin Sekunder Reaktor GA Siwabessy, Prosiding Seminar Nasional Teknologi dan Aplikasi Reaktor Nuklir PRSG,pp.65-70, 2014

[14] D.E.LESTARI, S.PUJIARTA, S.B.UTOMO., Pemantauan Korosi Pada Sistem Pendingin Dekunder Reaktor RSG-GAS Menggunakan Coupon Corrosion, Prosiding Seminar Nasional Teknologi dan Aplikasi Reaktor Nuklir, PRSG-BATAN, hal 125-131, 2016,

[15] E.RATNAWATI, D.T.JATMIKO, M.G.PERMADI.,Monitoring Lepasan Nuklida Dalam Air Pendingin Sekunder Dengan Pencacahan Langsung Di Reaktor RSG GAS, Prosiding Seminar Nasional Infrastruktur Energi Nuklir,pp137-142, 2019

[16]. JAJA SUKMANA, A.MARIATMA, J.A.KORUA., Kajian Keselamatan Operasi RSG-GAS Dengan Energi Terbangkit 660 MWD Menggunakan Program BATAN-2DIFF, Prosiding Seminar Nasional Teknologi dan Aplikasi Reaktor Nuklir, PRSG,pp.137-149, 2010.

[17] B. HERUTOMO, Laporan Operasi Reaktor RSG GAS Teras 89-95, PRSG-BATAN, 2015 